\title{
lodide Transporters in the Endometrium: A Potential Diagnostic Marker for Women with Recurrent Pregnancy Failures
}

\author{
Mahmood Y. Bilal ${ }^{a, b} \quad$ Svetlana Dambaeva ${ }^{a, b}$ David Brownstein ${ }^{c}$ \\ Joanne Kwak-Kim ${ }^{b, d}$ Alice Gilman-Sachs ${ }^{a, b}$ Kenneth D. Beaman ${ }^{a, b}$ \\ ${ }^{a}$ Clinical Immunology Laboratory, Rosalind Franklin University of Medicine and Science, North Chicago, IL, USA; \\ ${ }^{b}$ Department of Microbiology and Immunology, Chicago Medical School, Rosalind Franklin University of Medicine \\ and Science, North Chicago, IL, USA; ${ }^{C}$ Center for Holistic Medicine, West Bloomfield, MI, USA; ${ }^{\mathrm{d} D e p a r t m e n t}$ of \\ Obstetrics and Gynecology, Rosalind Franklin University Health System, Vernon Hills, IL, USA
}

\section{Significance of the Study}

- National Health and Nutrition Examination Survey studies show that a significant number of women in childbearing age do not have optimal levels of iodine.

- The need for iodine is not limited to the thyroid glands but its modulatory effects and transporters can be observed in a variety of cells.

- Women with reproductive failures had a significant increase of iodide transporters suggesting a localized iodine deficiency.

\section{Keywords}

lodine $\cdot$ Pregnancy failure $\cdot$ Endometrium $\cdot$ Sodium iodide symporter · PENDRIN

\begin{abstract}
Objective: The element iodine is an essential nutrient utilized by the thyroid glands, and deficiency of this element has been linked to reproductive failures. lodide transporters are also present in reproductive tissues and cells of embryonic origin such as the endometrium and trophoblasts, respectively. The aim of this study is to understand if levels of iodide transporters are linked to pregnancy outcomes. Subjects and Methods: RNA derived from endometrial biopsies from controls or women with recurrent reproductive failures was analyzed utilizing RT-PCR and targeted RNASeq. $\boldsymbol{R e}$ -
\end{abstract}

sults: When compared to controls, women with 2 or more reproductive failures had a significant increase ( $>5$ fold) in mRNA levels of the iodine transporters NIS and PENDRIN, but not thyroglobulin when probed vis RT-PCR. Targeted RNASeq analysis confirmed these findings when another group of patients were analyzed. Conclusion: These findings suggest possible abnormal iodine metabolism and a deficiency of iodine in endometrial tissues from some of the women with reproductive failures. We hypothesize from these findings that inorganic iodide and/or iodine is required for optimal cellular function in reproductive tissues, and that iodide transporters may potentially be used as a marker for infertility or for probing potential localized iodine deficiency that may not present in a typical thyroid panel analysis.

(c) 2020 The Author(s)

Published by S. Karger AG, Basel

$\begin{array}{ll}\text { karger@karger.com } & \begin{array}{l}\text { (c) 2020 The Author(s) } \\ \text { Published by S. Karger AG, Basel }\end{array} \\ \text { www.karger.com/mpp } & \text { This is an Open Access article licensed under the Creative Commons } \\ \text { Karger } & \begin{array}{l}\text { Attribution-NonCommercial-4.0 International License (CC BY-NC) } \\ \text { (http://www.karger.com/Services/OpenAccessLicense), applicable to } \\ \text { the online version of the article only. Usage and distribution for com- } \\ \text { mercial purposes requires written permission. }\end{array}\end{array}$

Kenneth D. Beaman

Department of Microbiology and Immunology Rosalind Franklin University of Medicine and Science 3333 Green Bay Road, North Chicago, IL 60064 (USA) Kenneth.Beaman@ rosalindfranklin.edu 


\section{Introduction}

Iodine is an essential element that cannot be manufactured in the body and must be obtained through dietary means to ensure adequate metabolic functions. Body organs, including the thyroid, concentrate iodine against a gradient and require adequate iodine levels to produce the necessary thyroid hormones. Production of thyroid hormones begins by the synthesis of thyroxine $\left(\mathrm{T}_{4}\right)$ in the thyroid glands wherein iodine is conjugated into tyrosyl compounds found on thyroglobulin (TG) with 4 and 3 iodine atoms present on $\mathrm{T}_{4}$ and the active hormone $\mathrm{T}_{3}$, respectively [1]. Therefore, without sufficient amounts of iodine obtained from the diet, optimal levels of these hormones cannot be produced. The recommended dietary/daily allowance (RDA) for iodine differs depending on age and pregnancy/lactation status. For example, it is indicated that adult males and females require 150 $\mu \mathrm{g}$ of iodine per day for optimal function. However, pregnant and lactating women require 220 and $290 \mu \mathrm{g}$ of iodine per day, respectively. Levels of iodine deficiency are determined through urinary iodine concentration (UIC) whereby levels $<100 \mu \mathrm{g} / \mathrm{L}$ UIC suggest a deficiency [2].

The World Health Organization (WHO) estimates that almost 2 billion people worldwide do not receive sufficient amounts of iodine [2]. As of today, this pertains to more than a quarter of the world's population. Similarly, recent work by the National Health and Nutrition Examination Survey (NHANES) demonstrated that approximately 38 and $35 \%$ of pregnant women and women in childbearing age, respectively, had $<100 \mu \mathrm{g} / \mathrm{L}$ UIC demonstrating insufficient iodine stores [2-4]. Moreover, about $58 \%$ of women in childbearing age had $<150$ $\mu \mathrm{g} / \mathrm{L}$ UIC, which is below the RDA for adult, pregnant, or lactating women. These numbers are substantial considering the massive effects of an iodine deficiency on human health including congenital hypothyroidism and mental retardation, reproductive failures, goiters, and reduced quality of life in adults attaining hypothyroidism $[5,6]$. Hence, early detection of iodine insufficiencies or deficiencies is critical in preventing irreversible fetal brain damage as well as the adult onset of hypothyroidism.

To date, any potential roles of inorganic iodine (iodide salts and molecular iodine) on cellular mechanisms (i.e., transcription, translation, survival, and metabolism) with regards to extrathyroidal cells have not been clearly established. This is important considering recent studies demonstrating the potential effects of inorganic iodine on cellular function $[1,7]$. Additionally, the current RDA of 150 $\mu \mathrm{g} /$ day for iodine was solely developed to prevent goiter formation and hypothyroidism as it did not take into account extrathyroidal iodine requirements. In our previous work, we established that inorganic iodine has direct effects on the transcriptional activity and subsequent cytokine release by human leukocytes [1]. We extrapolated that iodine could function as an immunomodulatory agent both in the periphery as well as in reproductive organs. This is of paramount importance as the immune system plays a role in providing growth milieu and cytokines which drive processes such as angiogenesis that aid in fetal development $[8,9]$. We also found that immune cells utilize TG to release $T_{4}$ and $T_{3}$, which will certainly affect reproductive tissues and the developing fetus [1].

Total body iodine stores have been estimated to be up to $25 \mathrm{mg}$ with the thyroid holding up to $70-80 \%$ of total iodine while the rest is distributed to other body organs $[10,11]$. However, the $70-80 \%$ number is true only during an iodine deficiency. Whole body iodine sufficiency is around $1,500 \mathrm{mg}$, which would lower the percentage that the thyroid holds to about $3.3 \%$ or $50 \mathrm{mg}$ of iodine [12]. The thyroid glands increase the levels of sodium iodide symporter (NIS) in order to absorb more iodide against a gradient from the plasma when the demand for more iodine is increased. Conversely, when iodine is present it can suppress NIS expression indicating a possible negative regulatory role [13]. Next, other bodily tissues or cells are also able to concentrate a significant amount of iodide including the ovaries, mammary glands, and leukocytes $[1,14,15]$. Since the current RDA values for iodine were meant to only prevent thyroidal goiters, other glands and organ systems may still be locally deficient in this mineral and may develop abnormal cellular transcriptional activity [1,7]. Moreover, for some patients, one cannot completely depend on so-called "normal thyroid panel" blood levels as the deficiency may still be present when the patient presents with normal range plasma thyroid hormone levels. For example, this was demonstrated by Venturi and Venturi [16] where schoolaged children (6-10 years) in an endemic goiter area were evaluated for immune deficiency induced by low iodine levels. It was found that $48 \%$ of these children had goiters and delayed immune responses despite some presenting with normallevels of thyroid stimulating hormone (TSH), $\mathrm{T}_{4}$, and $\mathrm{T}_{3}$. Upon therapeutic supplementation with $\mathrm{Lu}-$ gol's iodine, these children displayed normalized immune responses.

In this report, we have analyzed mRNA transcripts of iodide transporters, NIS and Solute Carrier Family 26 Member 6 (SLC26A6), also known as PENDRIN, in en- 
dometrial tissues from women with recurrent reproductive failures. Our analysis corroborates previous histochemical studies and demonstrates that some infertile or women with multiple reproductive failures harbor increased levels of iodide transporters when compared to controls that have had at least one successful pregnancy. From these results we hypothesize that localized iodine deficiency could be present in tissues such as the endometrium and may contribute to infertility or reproductive failures by affecting the local immune response and/or regulation of gene expression in reproductive tissues. Therefore, utilizing our data in conjunction with other previous work, we suggest that mRNA analysis of iodide transporters should be further investigated as a potential diagnostic marker in patients with recurrent pregnancy loss and repeated implantation failures or for probing potential localized iodine deficiencies.

\section{Subjects and Methods}

\section{RNA Extraction from Endometrial Biopsies}

Endometrial biopsy samples used in the study were collected from women that have been diagnosed with infertility, unexplained recurrent pregnancy loss/failures (RPF) with 2 or more consecutive miscarriages of unknown etiology or underwent assisted reproductive service and have a history of 2 or more failed embryo transfers. Control group consisted of healthy women in reproductive age with at least one successful pregnancy. There was no significant difference in age between the patient group $(n=60$, 35.7 years, 95\% CI 34.3-37 years) and controls ( $n=10,39$ years, 95\% CI 33.5-42.3 years). For the patient group used for RNASeq analysis $(n=42)$, the mean age was 36.2 years (95\% CI $34.5-38$ years). Study exclusion criteria included patients with endocrine disorders, polycystic ovarian syndrome, thrombophilia, hemophilia, or autoimmunity. The consent as well as the documentation process associated with these biopsy donors were approved by the IRB for Rosalind Franklin University of Medicine and Science. Endometrial biopsies were obtained during mid-luteal phase, 7-9 days after ovulation in natural cycles. Tissue samples were collected into RNAlater solution (Invitrogen). To extract RNA from the endometrial tissue, approximately $30 \mathrm{mg}$ of tissue was mixed with $500 \mu \mathrm{L}$ of Qiagen's RLT lysis buffer and $5 \mu \mathrm{L} 2$-mercaptoethanol. The tissue was immediately homogenized for $5 \mathrm{~min}$ with bead beating, centrifuged at 13,000 rpm for $3 \mathrm{~min}$, and then the supernatant was transferred to a new tube containing $250 \mu \mathrm{L}$ of $>99 \%$ ethyl alcohol. The solution was mixed, transferred to Qiagen's micro RNeazy columns, and then washed and eluted per manufacturer's recommendations.

\section{Purification and RNA Extraction from Peripheral Blood}

Leukocytes

Leukocytes from human peripheral blood were drawn in sodium heparin, extracted, and cultured as previously described [1]. Total RNA was extracted from leukocytes utilizing Qiagen's mini RNeazy kits per manufacture's recommendations.

\section{Reverse Transcription PCR/qPCR}

Reverse transcription and PCR reactions were performed utilizing $400 \mathrm{ng}$ of total RNA using Transcriptor first strand cDNA system (Roche) as previously described [1]. For gel electrophoresis analysis, $50 \mathrm{ng}$ of cDNA was amplified for 37 cycles with Platinum SuperFi II PCR kit (ThermoFisher). PCR conditions were performed per manufacturer's recommendations with annealing at $60^{\circ} \mathrm{C}$ for $10 \mathrm{~s}$ and extension at $72^{\circ} \mathrm{C}$ for $30 \mathrm{~s}$. The following primers were used for PCR amplification with all primers listed in the $5^{\prime} \rightarrow 3^{\prime}$ : NIS F 306 bp: CTCTTCATGCCCGTCTTCTAC, NIS R: GACAACCCAGAAGCCACTTA; PENDRIN F 320 bp: TCCTGTCGGATATGGTCTCTAC, PENDRIN R: GATCTGCCAAGTACCTCACTATG; GAPDH F 440 bp: ACATCATCCCTGCCTCTACT, GAPDH R: CTCTCTTCCTCTTGTGCTCTTG.

For quantitative real-time PCR, 50 ng of the cDNA was amplified with Taqman Fast Advanced Master Mix (Applied Biosystems) and then read with StepOnePlus real-time PCR instrument (Applied Biosystems). The following validated Taqman primers and probe were obtained from Invitrogen: NIS: Hs00950365_m1, PENDRIN: Hs01070627_m1, TG: Hs00174974_m1, B2M: Hs00187842_m1. Internal B2M Ct values were subtracted from each amplification reaction to attain dCt. Gene expression values were determined using the equation $2^{-\mathrm{dCt}}$.

\section{Targeted RNASeq}

Sequencing of RNA from endometrial tissue was performed per Qiagen's targeted RNASeq protocol as previously described [1]. Briefly, $50 \mathrm{ng}$ of RNA was utilized for cDNA synthesis, and then unique molecular barcodes were inserted through gene-specific primer extension for a total of 50 genes. These molecular barcodes allow for detection and quantification of unique cDNA transcripts and subsequent removal of duplicate transcripts via bioinformatics (i.e., cDNA copies amplified from the same molecular barcode strand will yield a call of one transcript). After a round of post-reaction purification, 2 more PCR reactions were performed to further amplify the set of 50 genes while adding index sequences that allow sample multiplex for next-generation sequencing (NGS). NGS was performed on Illumina's MiSeq instrument per manufacturer's recommendations with all quality controls, including cluster density, total reads, and percent reads reaching Q30 performing within optimal ranges provided by Illumina. FASTQ files were analyzed via Qiagen's GeneRead DNAseq variant calling service. The data were then exported into a format that provides total unique molecular barcode reads per gene. All reads were normalized to 10 internal control housekeeping genes (C16orf13, FBRSL1, KIAA0586, MAP3K2, PPIE, PPIL2, RFX1, THAP3, ZBTB22, ZNF446) after screening negative for genomic DNA contamination. For Heatmap analysis, the normalized sequencing data was uploaded into the open-source software "Morpheus" (https://software.broadinstitute.org/Morpheus). Since different genes have a wide range of expression, each gene column was adjusted or normalized separately to facilitate relative comparisons between patients and controls.

\section{Statistical Analysis}

Analysis and graphs for all data were performed utilizing GraphPad Prism and Microsoft Excel softwares using two-tailed $t$ test assuming unequal variance with normal distribution. 


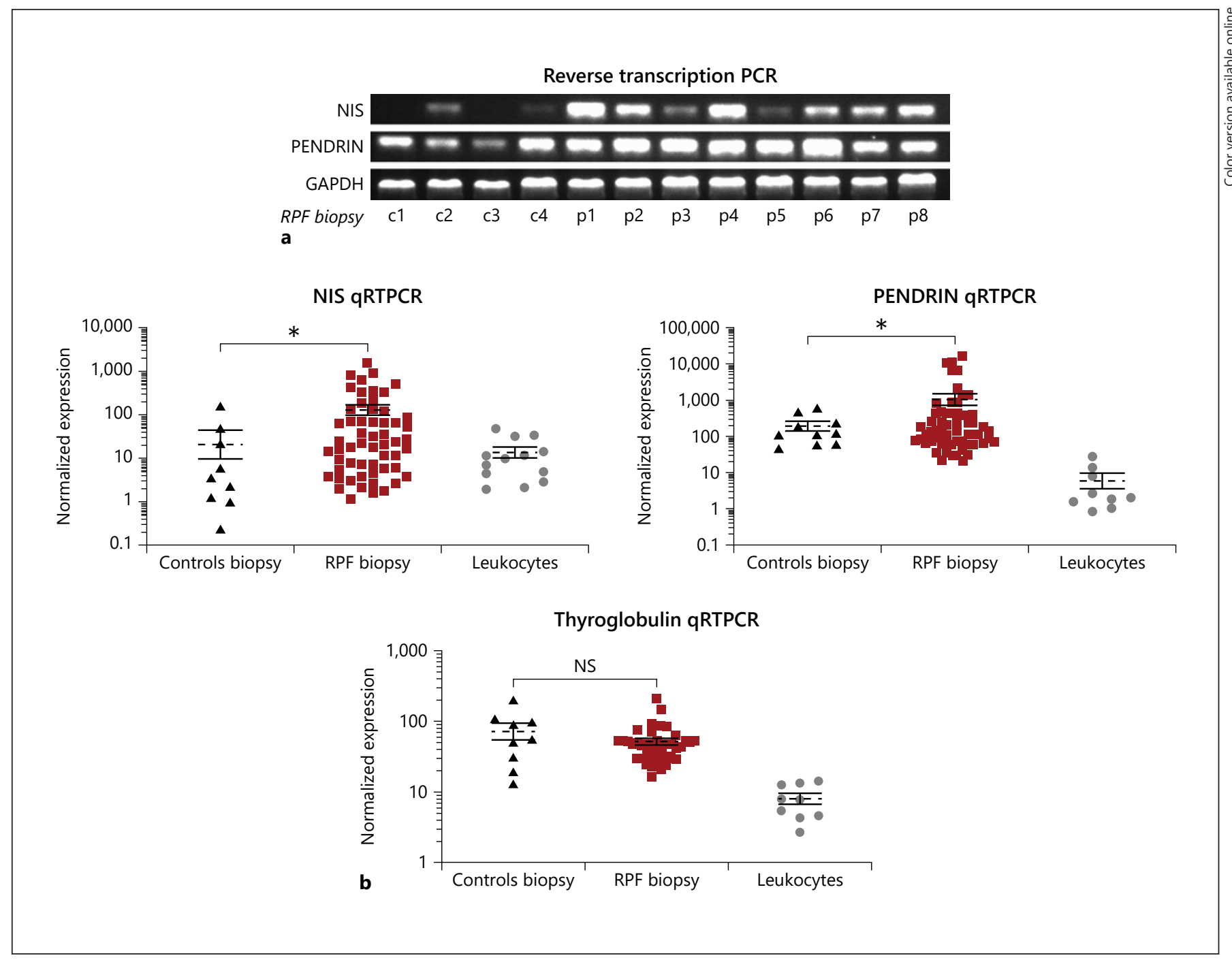

Fig. 1. Endometrial biopsies from women with RPF express higher transcript levels of NIS and PENDRIN. Midluteal phase endometrial biopsy tissue was obtained from patients (RPF) or control biopsies. Leukocytes were obtained from peripheral blood of healthy volunteers. a DNA gel electrophoresis from amplified RT-PCR products representing 4 controls ( $\mathrm{c} 1-\mathrm{c} 4)$ and 8 patient (p1-p8) biopsies. b Quantitative RT-PCR: normalized gene expression (to internal B2M) comparing control and RPF groups along with leukocytes represented as mean \pm SEM. NIS RPF $n=57$, PENDRIN RPF $n=60$, TG RPF $n=40 .{ }^{*} p<0.05$. NS, not significant.

\section{Results}

Endometrium from women with RPF expresses elevated levels of the iodide transporters NIS and PENDRIN. Iodine has been shown to affect cellular transcription, differentiation, and migration process in trophoblasts, which are of embryonic origin, in a similar manner to recent studies with leukocytes $[1,17]$. Additionally, iodine treatment increased Glial Cell Missing-1 (GCM-1) expression in trophoblastic cells. GCM-1 is a cellular dif- ferentiation marker expressed in the placenta and its expression is reduced in women with preeclampsia $[17,18]$. Given that transporters of iodide have been found in endometrial tissue, it is plausible that similar to leukocytes and trophoblastic cells, iodine could affect the functional activity of cells in reproductive tissues including the endometrium $[15,19]$. Typically, systemic iodine deficiency leads to increases in TSH and subsequent elevation of NIS in the thyroid glands. However, increased doses of iodine itself have been shown to downregulate NIS by reducing 
its mRNA and protein levels $[13,20]$. Accordingly, it is possible that low iodine levels could cause an increase of NIS mRNA by the mechanisms above. Previous findings showed that women suffering from idiopathic sterility display higher histochemical staining of NIS relative to fertile women [15]. We expanded on these previous reports and asked if the endometrium of women with RPF harbors molecular RNA changes in 2 transporters.

RNA was extracted from mid-luteal phase endometrium obtained from women with RPF or control endometrium from women with known successful pregnancies. Quantitative reverse transcription PCR analysis was performed on these samples for levels of NIS, PENDRIN, and TG. We first demonstrate that transcripts of NIS and PENDRIN are expressed in the endometrium as shown by the expected DNA bands on gel electrophoresis (Fig. 1a). As shown, the levels of NIS or PENDRIN fluctuate between different patients and are generally lower in controls. Next, confirming previous histochemical results, NIS expression was significantly higher, average 5 -fold, in women with RPF ( $n=57$; Fig. 1 b; Table 1$)$; as a reference, gene expression values for peripheral blood leukocytes were included. Interestingly, PENDRIN expression, which has not been previously determined, was also increased by approximately 5.5 -fold, but had a less variable pattern in controls compared to subjects with RPF ( $n=60$; Fig. 1b; Table 1). On the other hand, levels of TG transcripts $(n=40)$ were not statistically significant between the 2 groups (Fig. 1b; Table 1).

To confirm these results, we utilized samples from 42 other women with RPF and then performed targeted RNASeq analysis on 50 genes including some that are re- lated to immunity and inflammation - a process known to have negative effects in fertility if left unbalanced [9]. These genes include C1QA, C1QB, C1Q, TNFa, and IL10. All samples were normalized to ten housekeeping genes. The comparison was made against 6 controls due to sample limitation. Post normalization, we found that Beta-2 Microglobulin (B2M), which is considered another housekeeping gene and should be similar between all groups, had no significant differences between control and RPF biopsies (Fig. 2a, b). Next, we did not find any statistically significant differences for most of the gene panel probed with targeted RNASeq including TNFa and IL10 (Fig. 2b). However, in agreement with quantitative reverse transcription PCR analysis, NIS (SLC5A5) and PENDRIN (SLC26A4) showed significant increased expression $(>14$ fold and $>5$-fold, respectively) in this set of patients with RPF compared to controls (Fig. 2a, b). Overall, these observations suggest that NIS and PENDRIN could be used as a diagnostic marker to determine infertile reproductive tissue. These markers may also be used to probe the possibility of iodine deficiency in some women with recurrent reproductive failures, and iodine sufficiency levels in these women should be further investigated.

\section{Discussion}

In this report, we describe clinical data showing increased expression of iodide transporters in the endometrium of women with reproductive failures. Our molecular analysis confirmed the previous study utilizing immunohistochemistry staining, which demonstrated increased

Table 1. Quantitative reverse transcription PCR analysis - statistics from experiments shown in Figure 1b

\begin{tabular}{lcrlrl}
\hline & $\begin{array}{l}\text { Arithmetic } \\
\text { mean }\end{array}$ & \multicolumn{1}{l}{ SD } & \multicolumn{1}{l}{$\begin{array}{l}\text { Lowest } \\
\text { value }\end{array}$} & \multicolumn{1}{l}{$\begin{array}{l}\text { Highest } \\
\text { value }\end{array}$} & $\begin{array}{l}p \text { value } \\
\text { (controls vs. RPF) }\end{array}$ \\
\hline NIS - controls & 26.99 & 51.69 & 0.24 & 158.4 & 0.01018 \\
NIS - RPF & 133.77 & 274.94 & 1.18 & $1,529.7$ & \\
PENDRIN - controls & 202.05 & 192.06 & 46.57 & 614.7 & 0.02601 \\
PENDRIN - RPF & $1,114.42$ & $3,062.35$ & 20.62 & $16,854.1$ & \\
TG - controls & 74.5 & 59.25 & 13.07 & 202.8 & 0.29961 \\
TG - RPF & 51.95 & 35.48 & 16.3 & 211.7 & \\
\hline
\end{tabular}

Fig. 2. Targeted RNASeq analysis of endometrial biopsies. Endometrial biopsy tissue was obtained from 42 more patients not utilized in q-RTPCR analysis. a Quantified expression from RNASeq analysis for one control gene (B2M) and NIS and PENDRIN represented as mean \pm SEM. RPF $n=42$. b Heatmap analysis was created utilizing "Morpheus" software. ${ }^{*} p<0.05,{ }^{* *} p<0.005$. NS, not significant.

(For figure see next page.) 
NIS (SLC5A5) - targeted RNASeq

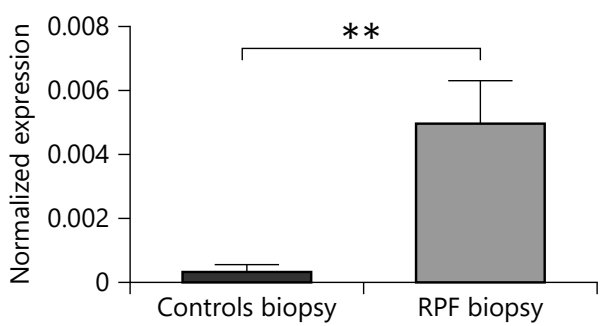

PENDRIN (SLC26A4) - targeted

RNASeq

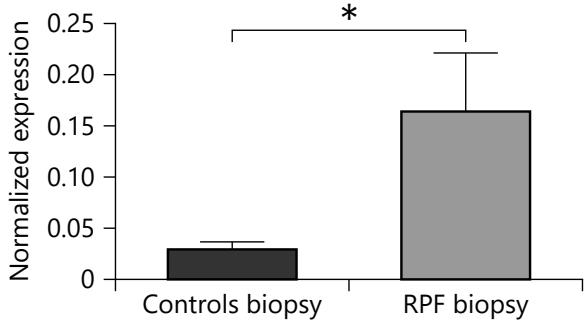

B2M - targeted RNASeq

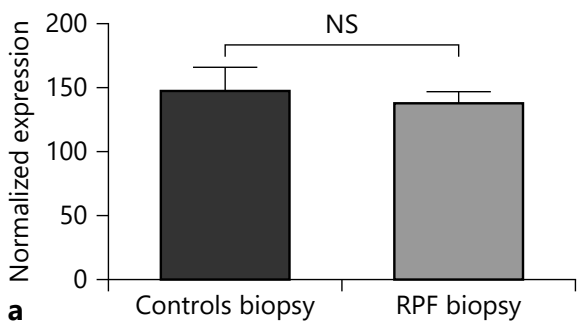

MAX

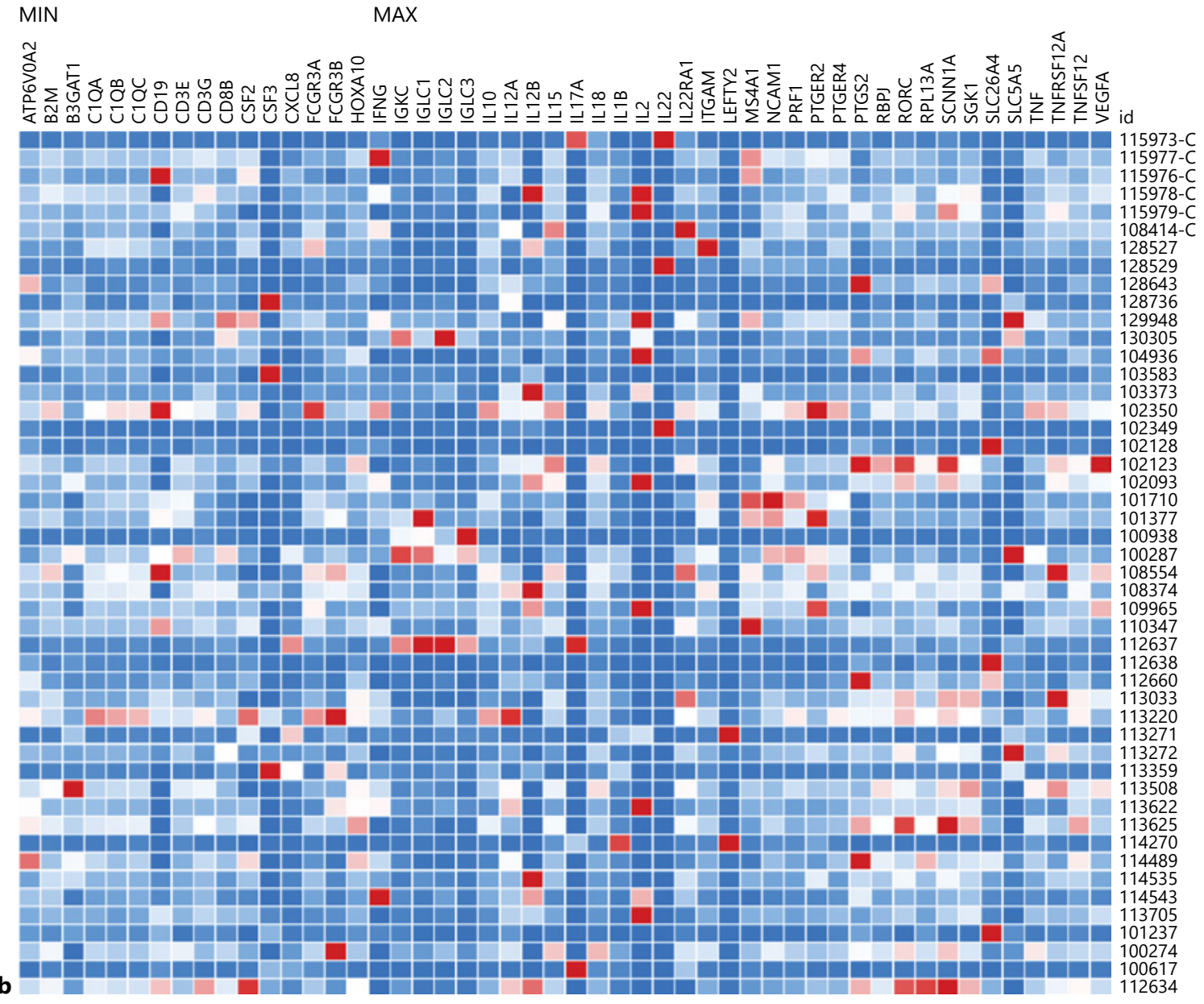


expression of endometrial NIS in infertile women compared to controls [15]. In like manner, average mRNA levels of PENDRIN were substantially elevated in endometrial tissues of women with reproductive failures compared to women who had successful pregnancies. These data suggest that an abnormal iodine metabolism and an iodine deficiency could be the reason for some of the observed reproductive failures.

Iodine is an essential component needed for a successful healthy pregnancy. The requirement for iodine during pregnancy is substantially increased, by $>50 \%$, for multiple reasons [11]. First there is an increased demand for $\mathrm{T}_{4}$ production as it is needed by the fetus in the first trimester [11]. This fetal requirement along with hormonal changes in pregnancy causes alteration in the mother's thyroid hormone homeostasis and subsequent increased maternal $\mathrm{T}_{4}$ synthesis (30-100\% more than pre-pregnancy levels) [21]. Second, the fetus utilizes iodine in later trimesters in order to make fetal thyroid hormones. Third, pregnant women have increased iodine clearance/ loss [11]. Alteration of thyroid hormone levels due to iodine deficiencies can lead to fetal neurological damage, congenital hypothyroidism, miscarriages, and eventual reproductive failures $[11,22]$. Worldwide analysis by the WHO illustrates that iodine deficiencies are prevalent and that includes women in childbearing age $[2-5,11]$. For these reasons, early detection of a deficiency is essential for the health of the fetus and newborn babies. The mechanisms utilized by iodine are mediated organically (via thyroid hormones) and inorganically (iodides and molecular iodine). We propose here that although organically bound iodine in the form of hormones is essential, iodides and molecular iodine could also play a part in optimizing reproductive organs and pregnancy. The mechanisms that stem from the actions of inorganic iodine/ iodide for regulation of reproductive tissues or immune cells are largely unexplored but have been shown to include transcriptional regulation of differentiation factors, hormone and lipid metabolism, and activation of cytokine release by tissue-resident immune cells (Fig. 3) [1, 7, $17,18]$. Further studies are needed to elucidate specifically how inorganic iodine or iodide affects the cellular functions of human reproductive tissues.

Recently, The NHANES reports demonstrated that approximately $58 \%$ of women in childbearing age have iodine intakes below the established RDA levels [3, 4]. Our molecular analysis shows elevated iodide transporters in some of patients with RPF compared to controls (Fig. 1b, 2a). An unanswered question stemming from these observations was what the meaning of elevated io- dide transporters in the endometrium is. We propose that localized iodine deficiency (i.e., sufficient thyroidal levels but insufficient levels in other organs) promotes increased expression of iodide transporters in affected cells. It is well established that NIS is upregulated directly by TSH stimulation due to feedback from low thyroid hormones originating from an iodine deficiency [23]. These transporters could also be regulated via hormone or cytokine signaling $[13,20,23]$. However, what is interesting is that NIS could also be altered directly by iodine wherein high levels of iodine suppress its expression $[20,23]$.

It is important to note that $\mathrm{TSH}$ or $\mathrm{T}_{4}$ do not always correlate with an iodine deficiency, and normal range levels of these analytes may be misleading with regards to iodine sufficiency $[16,24,25]$. The current iodine RDA values are meant to optimize thyroid levels, but have no bearing on secondary iodine concentrating organs/cells. Even with these current RDA levels, iodine deficiency continues to be a problem worldwide suggesting that secondary organs (i.e., other than thyroid glands) bear the consequences of suboptimal iodine levels. The human body may prioritize iodine to be first used in thyroid hormone production followed by the use in extrathyroidal tissues. Further research will be needed to delineate these ideas. Given these points, future studies should be considered to explore the role of iodide/iodine on the function of reproductive organs, and workups of infertility patients should include investigation of iodine sufficiency through simple spot urinary analysis, iodine loading test, or analysis of iodide transporters if endometrial biopsies are sampled.

Next, in the case of TG, as with other thyroid-related proteins, its role is poorly understood outside of the thyroid glands and studies for its expression in the endometrium are conflicting. For example, one report found that its transcripts and protein were undetectable in the endometrial tissue, while another report demonstrated small amount of transcripts that were confirmed by sequencing $[26,27]$. Here, we report amplification of TG transcripts from endometrial tissue (Fig. 1b). We believe the role of TG could be to facilitate minute amounts of thyroid hormones which is possible though not nearly to the extent of the thyroid glands [1,28-30]. Overall, our findings in conjunction with the direct role of iodine in regulating NIS, suggest that higher expression of NIS or PENDRIN in the endometrium of infertile women could be a response to either a systemic or a localized iodine deficiency (Fig. 3).

It is important to mention some limitations of this short study. First, there is absence of thyroid hormone 


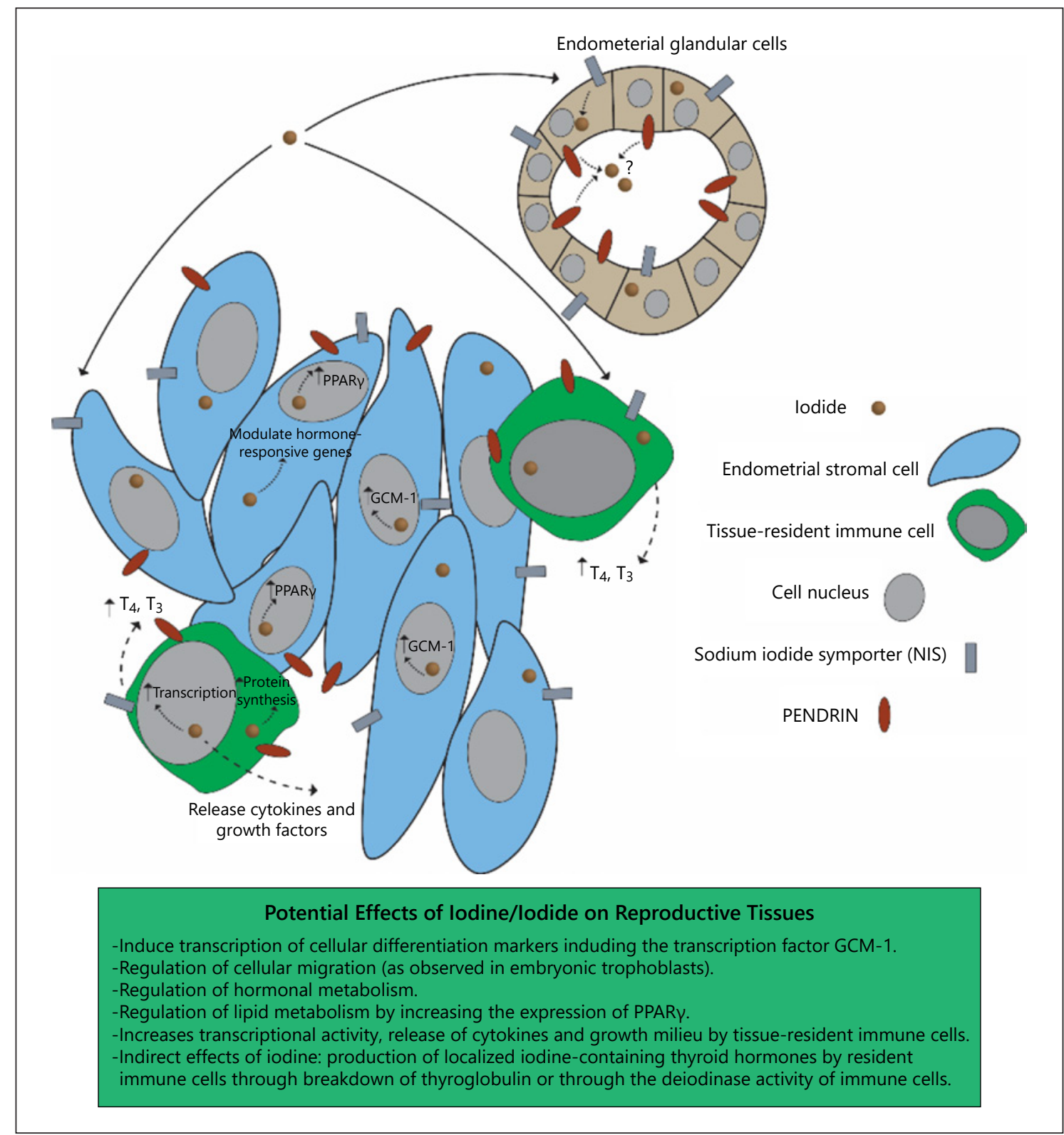

Fig. 3. Endometrial stromal and immune cells express iodide transporters utilized for iodide influx and alteration of cellular function. Iodine deficiency may occur either systemically involving the thyroid glands and the rest of body organs, or locally where the thyroid is sufficient but other organs are deficient. Based on previous work along with our findings, we suggest that endometrial cells (glandular and stromal) respond to iodine deficiency by upregulating the expression of iodide transporters to increase the chance of obtain-

testing, histological staining, and UIC analysis in these samples, which was due to either absence of clinical data or insufficient tissue quantity. In particular, although a previous histological study agrees with our findings, his- ing more iodide from the surrounding cellular environment. Alteration of iodide transporters may be monitored with molecular analysis as patients undergo endometrial biopsy procedures. Upon obtaining optimal levels of iodine, reproductive organs and surrounding immune cells respond by altering multiple cellular pathways which include transcription, cytokine and growth factor release, and regulation of hormone metabolism. Immune cells may also increase the amount of thyroid hormones locally.

tological studies of the same patients shown here would have determined cellular orientation of the iodide transporters. This is important since PENDRIN is known to be localized on the apical surface of cells in order to promote 
iodide efflux, but it may also be involved in iodide influx into the cytoplasm via iodide/chloride exchange $[31,32]$. It is also important to note that PENDRIN is not specific to iodide but may also import other halogens including chloride. However, PENDRIN itself cannot be completely compensated for with regards to iodide metabolism, as malfunction of this protein results in hypothyroidism as demonstrated in Pendred syndrome (https:/ghr.nlm. nih.gov/). We speculate that in the case of the endometrium, PENDRIN is increased to facilitate iodide influx into the cytoplasm, but we cannot rule out other possible mechanisms related to thyroid hormone synthesis whereby PENDRIN facilitates iodide metabolism into the endometrial lumen in a similar manner to thyroid follicular lumen. Overall, our results confirm previous work utilizing antibody-based staining whereby women with infertility had significant increase of NIS surface protein levels [15]. Second, the endometrium contains multiple types of cells such as stromal, glandular, and immune cells. Since our analysis was based on RNA, we cannot delineate what cells express these transporters or if the expression is limited to only one cell type. Trovato et al. [15] demonstrated that NIS is expressed in glandular and endometrial stromal cells, but the authors did not probe the expression of PENDRIN. Finally, the patient population is mixed and includes women that have been diagnosed with infertility, unexplained RPF of unknown etiology or underwent assisted reproductive service and have history of failed embryo transfers. Therefore, our data does not differentiate or quantify the differences between the 2 populations.

Future studies should determine if the observed increased level of iodide transporters is specific to one population or if it can be demonstrated with different diagnoses.

\section{Conclusion}

Our data suggest further investigation into the role of iodide transporters in female reproductive organs and the possibility of iodine deficiency in women with reproductive failures of unknown etiology even in the presence of normal thyroid hormones. We also recommend an establishment and review of the optimal iodine levels needed to saturate non-thyroidal organs.

\section{Acknowledgments}

The authors thank Drs. Alfredo Germain, Emilio Fernandez, and coworkers from Reproductive Medicine, Clinica las Condes for their support and sharing clinical biopsy samples.

\section{Statement of Ethics}

The consent as well as the documentation process associated with these biopsy donors were approved by the IRB for Rosalind Franklin University of Medicine and Science.

\section{Conflict of Interest Statement}

The authors declare that the research was conducted in the absence of any commercial or financial relationships that could be construed as a potential conflict of interest.

\section{Author Contributions}

M.Y.B. conceived, designed, and performed the experiments and interpreted the data. M.Y.B wrote the manuscript with input from all other authors. D.B., S.D., A.G.-S., and K.D.B contributed to study design and data analysis. J.K.-K. oversaw clinical assessment and recruitment of patients.

\section{References}

1 Bilal MY, Dambaeva S, Kwak-Kim J, GilmanSachs A, Beaman KD. A Role for Iodide and Thyroglobulin in Modulating the Function of Human Immune Cells. Front Immunol. 2017 Nov;8:1573.

2 Benoist B, Andersson M, Egli I, Takkouche B, Allen H. Iodine Status Worldwide. World Health Organization; 2004.

3 Caldwell KL, Makhmudov A, Ely E, Jones RL, Wang RY. Iodine status of the U.S. population, National Health and Nutrition Examination Survey, 2005-2006 and 2007-2008. Thyroid. 2011 Apr;21(4):419-27.

4 Leung AM, Pearce EN, Braverman LE. Iodine nutrition in pregnancy and lactation. Endo- crinol Metab Clin North Am. 2011 Dec;40(4): 765-77.

5 Dillon JC, Milliez J. Reproductive failure in women living in iodine deficient areas of West Africa. BJOG. 2000 May;107(5):631-6.

6 Pérez-López FR. Iodine and thyroid hormones during pregnancy and postpartum. Gynecol Endocrinol. 2007 Jul;23(7):414-28.

7 Stoddard FR 2nd, Brooks AD, Eskin BA, Johannes GJ. Iodine alters gene expression in the MCF7 breast cancer cell line: evidence for an anti-estrogen effect of iodine. Int J Med Sci. 2008 Jul;5(4):189-96.

8 Mor G, Cardenas I, Abrahams V, Guller S. Inflammation and pregnancy: the role of the im- mune system at the implantation site. Ann N Y Acad Sci. 2011 Mar;1221(1):80-7.

9 Beaman KD, Dambaeva S, Katara GK, Kulshrestha A, Gilman-Sachs A. The immune response in pregnancy and in cancer is active and supportive of placental and tumor cell growth not their destruction. Gynecol Oncol. 2017 Jun; 145(3):476-80.

10 Hays MT. Estimation of total body iodine content in normal young men. Thyroid. 2001 Jul;11(7):671-5.

11 Zimmermann MB. The effects of iodine deficiency in pregnancy and infancy. Paediatr Perinat Epidemiol. 2012 Jul;26 Suppl 1:10817. 
12 Abraham G. Serum Inorganic Iodide Levels Following Ingestion of a Tablet Form of Lugol Solution: Evidence for an Enterohepatic Circulation of Iodine. Original Internist. 2004; 11:29-38.

13 Uyttersprot N, Pelgrims N, Carrasco N, Gervy C, Maenhaut C, Dumont JE, et al. Moderate doses of iodide in vivo inhibit cell proliferation and the expression of thyroperoxidase and $\mathrm{Na}+/ \mathrm{I}-$ symporter mRNAs in dog thyroid. Mol Cell Endocrinol. 1997 Aug;131(2): 195-203.

14 Spitzweg C, Joba W, Eisenmenger W, Heufelder AE. Analysis of human sodium iodide symporter gene expression in extrathyroidal tissues and cloning of its complementary deoxyribonucleic acids from salivary gland, mammary gland, and gastric mucosa. J Clin Endocrinol Metab. 1998 May;83(5):1746-51.

15 Trovato M, Vitarelli E, Tripepi M, Abate A, Rizzo P, Benedetto V, et al. Expression of NA/1 symporter (NIS) in endometrial mucosa of fertile, sterile and post-menopausal women. Histol Histopathol. 2008 May;23(5):549-54.

16 Venturi S, Venturi M. Iodine, thymus, and immunity. Nutrition. 2009 Sep;25(9):977-9.

17 Olivo-Vidal ZE, Rodríguez RC, Arroyo-Helguera O. Iodine Affects Differentiation and Migration Process in Trophoblastic Cells. Biol Trace Elem Res. 2016 Feb;169(2):180-8.

18 Chen CP, Chen CY, Yang YC, Su TH, Chen H. Decreased placental GCM1 (glial cells missing) gene expression in pre-eclampsia. Placenta. 2004 May;25(5):413-21.
19 Wapnir IL, van de Rijn M, Nowels K, Amenta PS, Walton K, Montgomery K, et al. Immunohistochemical profile of the sodium/iodide symporter in thyroid, breast, and other carcinomas using high density tissue microarrays and conventional sections. J Clin Endocrinol Metab. 2003 Apr;88(4):1880-8.

20 Spitzweg C, Joba W, Morris JC, Heufelder AE. Regulation of sodium iodide symporter gene expression in FRTL-5 rat thyroid cells. Thyroid. 1999 Aug;9(8):821-30.

21 Cignini P, Cafà EV, Giorlandino C, Capriglione S, Spata A, Dugo N. Thyroid physiology and common diseases in pregnancy: review of literature. J Prenat Med. 2012 Oct; 6(4):64-71.

22 Kapil U. Health consequences of iodine deficiency. Sultan Qaboos Univ Med J. 2007 Dec; 7(3):267-72.

23 Dohán O, De la Vieja A, Paroder V, Riedel C, Artani M, Reed M, et al. The sodium/iodide Symporter (NIS): characterization, regulation, and medical significance. Endocr Rev. 2003 Feb;24(1):48-77.

24 Bhattacharjee A, Chandra AK. Tiwari3 HK, Malik T. Serum thyroid hormone and thyrotropin levels in school children from goiter endemic sub-Himalayan tarai region of Eastern Uttar Pradesh, India. Curr Pediatr Res. 2013;17:27-30.

25 Ma ZF, Skeaff SA. Thyroglobulin as a biomarker of iodine deficiency: a review. Thyroid. 2014 Aug;24(8):1195-209.
26 Catalano RD, Critchley HO, Heikinheimo O, Baird DT, Hapangama D, Sherwin JR, et al. Mifepristone induced progesterone withdrawal reveals novel regulatory pathways in human endometrium. Mol Hum Reprod. 2007 Sep;13(9):641-54.

27 Moravvej A, Jeddi-Tehrani M, Moghaddam AR, Dokouhaki P, Shekarabi M, Ghods R, et al. Assessment of thyroglobulin expression in reproductive organs at different stages of mouse estrous cycle. Avicenna J Med Biotechnol. 2009 Apr;1(1):41-6.

28 Meischl C, Buermans HP, Hazes T, Zuidwijk MJ, Musters RJ, Boer C, et al. H9c2 cardiomyoblasts produce thyroid hormone. Am J Physiol Cell Physiol. 2008 May;294(5):C1227-33.

29 Stolc V. Stimulation of iodoproteins and thyroxine formation in human leukocytes by phagocytosis. Biochem Biophys Res Commun. 1971 Oct;45(1):159-66.

30 Obregon MJ, Mallol J, Escobar del Rey F, Morreale de Escobar G. Presence of L-thyroxine and 3,5,3'-triiodo-L-thyronine in tissues from thyroidectomized rats. Endocrinology. 1981 Sep;109(3):908-13.

31 Bernardinelli E, Costa R, Nofziger C, Paulmichl M, Dossena S. Effect of Known Inhibitors of Ion Transport on Pendrin (SLC26A4) Activity in a Human Kidney Cell Line. Cell Physiol Biochem. 2016;38(5): 1984-98.

32 Bizhanova A, Kopp P. Minireview: the sodium-iodide symporter NIS and pendrin in iodide homeostasis of the thyroid. Endocrinology. 2009 Mar; 150(3):1084-90. 